\title{
Nicotine stomatitis in a heavy smoker man with chronic psychosis
}

\section{Kronik psikozlu ağır sigara içici bir erkekte nikotin stomatiti}

\author{
Habibullah Aktas ${ }^{1}$ \\ ${ }^{1}$ Dept. of Dermatology, Karabuk University, Faculty of Medicine, Karabuk, Turkey
}

Dear editor,

Nicotine stomatitis is a whitish papuler lesion seen on the hard and soft palate in the oral cavity, possibly caused by blockage of palatal mucous glands. This specific entity usually occurs in pipe users, but is also observed in cigar and cigarette smokers and in individiuals who have hot beverage habit. So, there is a proposition that heat causes to nicotine stomatitis rather than toxic materials., ${ }^{1,2}$

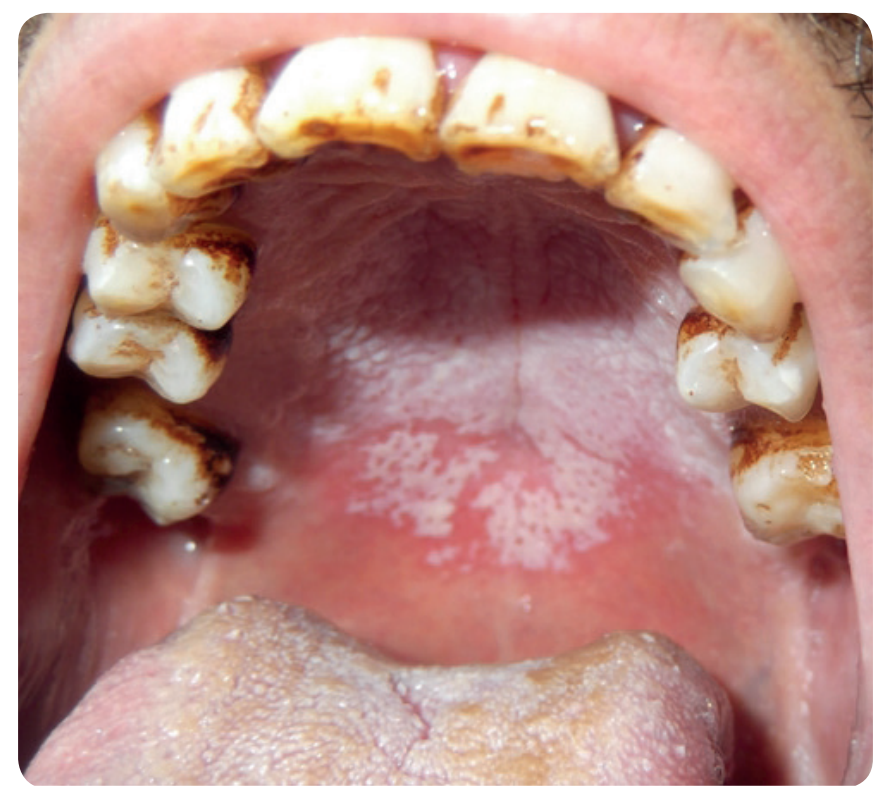

Fig. 1. Numereous whitish coalesced papules and plaques with occasional red punctate areas
A 47-year-old male presented to our dermatology clinic for which he noticed a whitish lesion on the palatal area. In dermatological examination, numereous whitish coalesced papules and plaques with occasional red punctate areas were observed (Fig.1). The patient has been followed with a diagnosis of chronic psychosis for years. He has been a cigarette smoker with four packs a day for at least six years. Neither his physicians nor his family warned him to stop smoking since smoking would be expected to reduce his psychiatric symptoms. The patient has been taking some antipsychotic agents unregularly. Differential diagnoses of nicotine stomatitis include oral candidiasis, leukoplakia, squamous cell carcinoma, frictional keratosis, lichenoid reactions and several others. ${ }^{3}$

A clinical diagnosis of nicotine stomatitis was done, and it was suggested him to cease or significantly decrease smoking.

The lesions in nicotine stomatitis resemble cobblestones just like in this case. Although this disorder is mostly related to pipe smoking and cigar smoking, it can also be observed in heavy cigarette smokers. ${ }^{2}$ Psychological condition of our patient might be an indirect cause of nicotine stomatitis, leading his to be a heavy cigarette smoker.

White oral lesions cause anxiety both in patients and physicians because of their malignant potential. Alt-

Key words: nicotine stomatitis

Corresponding author: Habibullah Aktas, Dept. of Dermatology, Karabuk University, Faculty of Medicine, Karabuk, Turkey, Phone: +90 53240846 11, E-mail: aktashabib@hotmail.com

Received: 1 June 2019 Accepted: 18 June 2019

Conflicts of Interest: None 
hough there is a close relationship between smoking and nicotine stomatitis, a malignant degeneration is not expected in nicotine stomatitis lesions. ${ }^{4}$ Smoking cessation usually completely results in a recovery of the lesion within two to three weeks.

Oral lichen planus and leukoplakia are examples of white oral lesions sometimes developing malignant squamous carcinoma. ${ }^{5}$ That's why it is crucial to discriminate oral whitish lesions from premalignant counterparts.

Rossie and Guggenheimer reported a case clinically mimicking nicotine stomatitis in a woman who had no history of smoking. However, she had been exposed to excessive hot beverages. Her lesion had improved after discontinuation of that habit. 6 In this presented case, it would be better to differentiate oral candidiasis and other white oral lesions by a native preparation and/or mucosal biopsy, however clinical appearance and heavy cigarette smoking history with the psychological condition of the patient reluctant to any medical intervention have been considered sufficient for a definite diagnosis.

\section{References}

1. Schwartz DL. Stomatitis nicotina of the palate: Report of two cases. Oral Surg Oral Med Oral Pathol 1965;20:306-15.

2. dos Santos RB, Katz J. Nicotinic stomatitis: positive correlation with heat in maté tea drinks and smoking. Quintessence Int 2009;40:537-40.

3. Mortazavi H, Safi Y, Baharvand M, et al. Oral white lesions: an updated clinical diagnostic decision tree. Dent J 2019;7:15.

4. Mirbod SM, Ahing SI. Tobacco-associated lesions of the oral cavity: part I. nonmalignant lesions. J Can Dent Assoc 2000;66:252-6.

5. Gurbuz O. Precancerous lesions of the oral mucosa. Turkderm 2012;46 Suppl 2:86-9.

6. Rossie KM, Guggenheimer J. Thermally induced 'nicotine' stomatitis. A case report. Oral Surg Oral Med Oral Pathol 1990;70:597-9. 